\title{
For Foreign-Oriented Chinese Literature Translation, What Inspirations Can Be Derived from the Carrying out of the
} Translation Project of the King James Version of The Bible?*

\begin{abstract}
ZHANG Xi-zhi
South China Business College (SCBC), Guangdong University of Foreign Studies (GDUFS), Guangdong, China

Inspired by the "One Belt, One Road" initiative and the "Going Global" strategy, China has become more deeply involved in foreign exchange. The introduction of Chinese literature to the outside world has been part of China's soft-power strategy. However, it must be acknowledged that the quality of Chinese literature translation is not satisfactory for several reasons: essentially, issues relating to project management, translators' qualifications, and translation quality control. This essay reviews the translation practice that gave rise to the King James Bible (KJB), with a focus on its project management, translators' qualifications and quality control. It is hoped that this will serve to enlighten professionals in the field of Chinese literature translation.
\end{abstract}

Keywords: KJB, translation, foreign-oriented literature translation, Chinese literature

\section{Introduction}

At a 1604 imperial conference of bishops and theologians at Hampton Court Palace, a proposal was put forward that a new English translation of the Bible was published to win the acceptance of all churches. King James readily agreed. This new edition, known as the King James Bible (KJB) or simply the Authorized Version $(A V)$, was published in May of 1611 for the first time. Although that translation project happened more than 400 years ago, it is still relevant to modern China's large-scale translation projects, such as the translation of Chinese literature.

With regard to foreign-oriented translation of Chinese literature, the State Administration of Press Publication, Radio, Film, and Television of the People's Republic of China (SAPPRFT, 2017) launched the Classic Chinese International Publishing Project, the Silk Road Book Project and the Contemporary Chinese Literary Works Translation Project by pooling the roles of some governmental organs and publishers for the

\footnotetext{
* Acknowledgements: This paper is funded by the Key Program of the English Language and Literature of Guangdong Province, 2016. This paper results from the relevant research supported by the subprojects of "The Training for China Accreditation Test for Translators and Interpreters" and "New Era Renovation Team for the Study of Chinese-English Literature Comparison" (Ref: South China Business College 2017298), which belong to the project of Guangdong Key Characteristic Discipline (English Language and Culture) (2017, No. 1), the project of South China Business College (SCBC), Guangdong University of Foreign Studies (GDUFS) "Adaptive study on reform in teaching undergraduate Students in the World-English Era” (Ref: 2017JG09).

ZHANG Xi-zhi, MA in Translation, Lecturer at South China Business College (SCBC), Guangdong University of Foreign Studies (GDUFS), Guangdong, China
} 
purpose of pushing out quality foreign-oriented books that would successfully tell Chinese stories, convey Chinese voices and elucidate Chinese characteristics so that overseas readers would acquaint themselves with China, and furthermore, become familiar with and understand China. In terms of quantity, these projects have been advancing successfully. But in terms of quality, work on them is far from satisfactory.

In order to promote China's foreign-oriented literature translation, this paper aims to describe the process of translating the $K J B$, analyse helpful experiences that took place within this process, and put forward some suggestions highlighting the deficiencies that exist within present-day China's foreign-oriented literature translation projects.

\section{The Process of Translating the KJB}

Before the publication of the KJB, the most popular version was The Geneva Bible, which was the first complete edition translated from Hebrew plus Greek to English and was first numbered based on sentence groups; in addition, it was attached to large quantities of marginal notes and reference information (Yang, 2008, p. 82).

For all of the reasons stated above, the obvious Calvinist trend and the prejudicial marginal notes within it disgusted many people, including King James I. The King demanded a new Bible to unify all churches throughout the country. He convened a meeting involving 54 religious seniors and academic authorities, all of whom shouldered the task of retranslating the Bible at the King's request (Later the number of the actual participants was 47). From beginning to end, the translation project underwent rigorous processes.

Organisation and division of the work: The translating personnel was divided into six groups, each of which was engaged in a certain part of the translation process in churches in Oxford, Cambridge, and Westminster. A reviewing commission consisting of 12 members, with two members coming from each of the six groups, was responsible for checking and revising. When the commission had difficulty in dealing with any problem, all the translators would join in the discussion to try to solve it.

Translating principles and guidelines: As for translating the Old Testament, the Greek version and the Hebrew version served as the criteria. As for translating the New Testament, leading early English versions, especially William Tyndale's version, served as the criteria. As for the style and form, Bishops' Bible was considered as the model to follow. The marginal notes were limited to language and parallel paragraphs (Hong, 2013, p. 133).

The related languages were Hebrew, Greek, and Aramaic (The 21st Century Web, 2017).

Time span is that three years for translating and more than three years for reviewing.

The KJB is a world-renowned success and has been remaining a best seller to this day (Kang, 2011, p. 59). Geddes MacGregor, the philosopher, calls it "the most influential version of the most influential book in the world, in what is now its most influential language" (Shoulson, 2016, p. 89).

\section{Main Deficiencies in the Translation of Chinese Literature}

As a matter of fact the 1950s witnessed a series of government-initiated foreign-oriented literature translation projects on a considerable scale, among which the most significant one is the founding of the magazine Chinese Literature. Among the later leading events are the initiation of the Panda Series (1981), the initiation of the Library of Chinese Classics (Chinese-English bilingual) (1995), the founding of the Center for 
External Communication Studies attached to China International Publishing Group (CIPG), China Foreign Languages Publishing Administration and the launching of the "Disseminating Chinese Literature Overseas" Project (early 2010). The events stated above led to a great many Chinese literary works from pre-Chin periods to modern times being translated. Among the related translators, there are some famous masters, such as Xianyi, Gladys Yang, and Fu Lei, to name just a few. Despite some excellent translations, the general achievements of these projects are not very satisfactory in terms of the quality of the translated texts. Some American Sinologists criticise the Panda Series, even pointing out that some translations cannot be taken as literary translation due to their poor quality, with random deletions occurring within them (Wang, 2014, p. 147). The reasons why some of the translations are of poor quality are as follows.

\section{Deficiencies in Organising the Translation Process}

So far, no continuous and unitive programming and organising has ever been a feature of literature translation at state level in China. China has yielded an abundance of literature over many millennia; moreover, nowadays good works by excellent writers appear continually. The literary sea is so vast that several projects like the "Library of Chinese Classics" cannot meet the demands of translation. In the long run, in order to meet the needs of international cultural communication, stable organisation and long-term arrangements are indispensable. In 1953, the Communist Party of China (CPC) established and began to lead the Central Compilation and Translation Bureau. A lot of translators and foreign experts were installed in the bureau and a specific library and a research institute were established as subsidiary bodies. These measures were a great success in popularizing Marxism-Leninism and promoting socio-scientific studies. In contrast, never have such measures been taken with regard to literature translation in China.

Otherwise, in China, talented translators who have, at some point, made special contributions have not received enough financial support from the state. According to Chen Boxiang (2016, p. 104), the senior reviser of the Ministry of Culture, among the people who are granted a State Council special allowance, none are from the translation circles. As they are not necessarily financially secure, many excellent translators have to make extra income by teaching, lecturing, writing, and so forth. Under such circumstances, they cannot concentrate their minds on translation. This situation is unhelpful for accumulating their translation experiences and improving translation quality.

\section{Deficiencies in Translators' Competence}

Due to the disproportionate programme structure, students of foreign studies at higher institutions spent little time studying Chinese literature over the past three decades. Thus, graduates are far poorer in their scholarly knowledge of the Chinese language than senior foreign language experts. Although the course of "College Chinese" is set for non-Chinese majors, no unitive credit hours and teaching objectives are requested, and thus, the teaching of this course is usually arranged at random. In reality, this course is offered over two terms at most in the majority of universities and colleges. Even worse, it is often taught in big classes, each with over one hundred students. Obviously, this course has been relegated to optional status (Lin, 2016, p. 41). Therefore, it is difficult to improve students' cultivation of literature through this course. A more worrying fact is that students of foreign studies end their Chinese learning, especially studies on Chinese classical literature, prematurely. As is known to all, translating begins with the translator's reading and understanding of the source text. Without a 
thorough grasp of a literary text's meaning in terms of both words and context, the translator cannot convey the connotation and denotation of the source sentences in a foreign language. Of course, if a translator with a foreign-language education background is poor in Chinese studies, and in particular, if he/she lacks a proper understanding of Chinese literature works and culture, his/her literature translation can hardly be deemed to be a quality piece of work by overseas readers.

Another disadvantage in the translation circles is the lowness of the contribution fee in the average market, which dispirits ambitious young people and keeps them from realizing their dreams, becoming full-time translators. It is reported that the standard fee for latter-day literary translation is only 150-200 RMB yuan per thousand Chinese characters (Chen, 2017). Although a lot of people with Master's degrees in translation have graduated from universities in recent years, most of them, facing living pressure, choose companies or teaching posts for their career for the sake of decent incomes. Very few of them work as full-time translators, only a small part of whom are willing to be engaged in literary translation. According to a survey carried out by Beijing Foreign Studies University, because of the low standard fee only $5.7 \%$ of the translators would like to translate literary works (Zhao, 2013). It is common sense that it is impossible to become a capable self-reliant and successful translator for literary works without decades-long accumulation of linguistic knowledge. These days, young scholars are quicker than ever to turn away from translation as their main occupation, which harms the development of their translation skills and even the prospect of the cultivation of a future literature translation elite in this country.

\section{Deficiencies in Controlling Translation Quality}

Literature translation is time-consuming. Some profit-oriented publishing houses tend to minimize the time for translating and final proofreading and modifying. In order to quicken the translating of voluminous literary works, publishers often divide a book into parts and let a number of translators co-translate it. Liu Xiliang (2009, p. 7), president of the Translators Association of China (TAC), pointed out, nowadays, some translators vie for translating best sellers by means of dividing a book and making several or more than ten people share the work, each translating some paragraphs. During the process, no one is responsible for the final regulation and modification in a consonant and consistent style. As a result, a person's name or a place name in the original may be translated using a variety of names in the target text. Besides, tremendously different wording styles co-exist in the same book. Insiders all acknowledge that hasty final compilation and editing can never yield quality translation.

\section{Inspirations for Chinese Literary Translation Derived From the Carrying out of the Translation Project of the KJB}

In order to get rid of the deficiencies stated above, the author derives some inspirations from the project of the KJB and puts forward some solutions on the basis of these for the purpose of enhancing the quality of China's foreign-oriented literature translation.

\section{Inspiration on the Translating Organisation}

It is clear that the translating personnel for the $K J B$ was arranged in a rigorous manner in which members had their respective duties and they were required to help each other as the rule. In this organisation, consisting of 
dozens of people, no member was allowed to operate in a unique way. Before the initiation of the project, a clear, complete program was prepared. According to Dr./Prof. Pauline Croft's article (2011, p. 248), "The translating committee was to be divided into six companies of eight members, with six directors supervising them". Throughout the process, these three sub-teams in six places were under unitive arrangements. For the final stage, mutual examination and finalization of the whole work were all managed via careful arrangements (KJB Translators, 2017a).

It is worth noting that the project of the $K J B$ was supported with abundant funds. "The bishops were required to find livings for the Translators, of more than $£ 20$ per year-a decent income" (Croft, 2011, p. 248). This decent income guaranteed a care-free life for the translators and ensured that they spared no effort in their work.

Thus, it is clear that China's key projects related to foreign-oriented literary translation need support from the state. To be specific, the Ministry of Culture and Tourism and the Ministry of Education should set up a top-down management scheme for universities that have high-class translators and publishers that maintain a high academic level. Under this scheme, translators would enjoy a year-long academic vacation every seven years, following the practice of some overseas universities. In addition, during their paid academic holiday, translators would receive the majority of their salary from the state and their universities would pay the rest. This practice would allow all of the participants involved in these translation projects to be free from other tasks and would ensure that they could work on such projects without experiencing financial worries during certain periods.

\section{Inspirations from the Source Language Accomplishments of the KJB's Translators}

In retrospect of the process of translating the $K J B$, it must be noted that the source text version of the Bible was a combination of Hebrew, Greek, and Aramaic and that all of the 54 translators that worked on the KJB were famous scholars of these languages ( $\mathrm{Liu} \& \mathrm{Wu}, 2006$, p. 169). Without their involvement, this tremendous translation project could not have been completed because the original Bible dated back so far in time and the languages in it were very different and strange. All the sections of the Bible were very old. Only Job (being an exception), appeared at an unknown date. Pentateuch, the oldest section, appeared in $1400 \mathrm{BC}$. And the latter sections of the New Testament appeared at the end of the 1st century. When the KJB project was initiated, the newest sections of the Bible were more than 1,000 years old and the oldest sections more than 3,000 years old. Because of the old ages of all those sections, it was never easy even for scholars to understand the texts literally, not to mention their cultural connotative meanings. It was never easy to understand these ancient texts either in a literal or in a more profound sense.

Whilst experts in the various source languages were appointed for the KJB project, in China's translation circles, by contrast, no consensus has been reached on whether or not the initial translator for a huge foreign-oriented literature translation project should be an individual with a deep knowledge of Chinese literature.

It would appear to be common sense that the initial translators engaged in foreign-oriented Chinese literature translation ought to be experts in Chinese language and literature, especially in the case of a large-scale project. The question that naturally follows is: Who exactly is suitable to perform the initial translating task, experts whose mother tongue is a foreign language or those with Chinese as their native language? 
As Chinese characters are based on ideograms, completely different from alphabetic writing, it is very difficult for foreigners to master them, which determines that native-born Chinese translators, whose mother tongue is Chinese, boast natural advantages. In addition, native Chinese translators are naturally much more keenly aware of Chinese cultural events than most foreign sinologists. For instance, the eminent sinologist Howard Goldblatt comments that since foreign translators have experienced neither the Cultural Revolution, the Anti-Japanese War nor the contemporary Reform and Opening-up Policies in China, they, unlike Chinese translators, can never thoroughly understand Chinese literary works in spite of their linguistic attainment (Hu, 2010, p. 11).

In the long run, for the cause of Chinese literature translation curriculum reform in higher education is needed. It is necessary to focus double the amount of attention on Chinese-foreign studies at the undergraduate stage to encourage students with good bilingual foundations to develop in both languages, and also to set up literature-translation-oriented postgraduate and even postdoctoral studies. All in all, a specific talent cultivation system for the cause of Chinese literary translation is required.

\section{Inspirations on Translation Quality Control}

The strictly organized KJB project was carried out for nearly seven years. That was a painstaking process of perfection and polishment for words and expressions. King James attached such great importance to translation work that he supervised it periodically in person (British Broadcasting Corporation [BBC] Web, 2017). The whole Bible was divided into parts for translators to render and their translation quality or style might vary from one to another. However, the entire translation practice was presided over by Archbishop Lancelot Andrewes and it was finalised by Dr. Miles Smith after all translators crosschecked. In addition, Dr. Smith's linguistic competence was well-recorded as follows,

It has been noted that from his youth he constantly applied himself in reading the ancient classical authors in their own languages, and that Greek, Latin, Hebrew, Chaldaic, Syriac, and Arabic were almost as familiar to him as his native tongue (KJB Translators, 2017b).

In Section "Inspirations from the source language accomplishments of the KJB's translators" above, the author proposes that the translation projects depend on Chinese translators, but it does not mean that foreigners who speak the target languages as their mother tongues should be excluded. On the contrary, they may play an important role, especially in quality control in the final stage. Jialong Tang, an experienced translator translating between French and Chinese, admits that he dares not translate Chinese literature without the aid of a reviewer. All of his translations have been checked by French revisers (Shi \& Lv 2013, p. 59). Another example is Xianyi and Gladys Yang's translations, which were initially translated by Xianyi Yang and then checked by Gladys Yang. Their cooperation produced many excellent English versions of Chinese literature works. This cooperation pattern is similar to that of the translation process of the KJB project, although the former was not carried out at the national level. There is no doubt that foreign revisers are much more skillful when it comes to the modification process in target languages than their Chinese counterparts. Thus, they are more capable of making the translation as adaptable to a different country as possible by regulating it under the premise of loyalty, because they have grown up within the linguistic-cultural background of the target language and therefore are more familiar with their compatriots' psychological characteristics. Currently, the Chinese 
government offers a variety of scholarships to foreign students studying in China. Considering this situation, it is reasonable that an additional condition for acquiring the scholarship for Master's degree studies or higher in the liberal arts domain be put forward, this being a willingness to offer services that involve arranging and revising translations, etc., in foreign-oriented Chinese literature translation projects. In this way, their linguistic-cultural advantages can be fully applied to the foreign-oriented introduction of Chinese literature. In fact, some international students have already participated in translation work. Some of them work as part-time translators in translation agencies. Some provide translation and review services for books published by higher educational institutions. If their services can be expanded to more fields, especially those of Chinese literature translation, the translation quality will be greatly improved.

\section{Conclusion}

The KJB has enjoyed great popularity in the English-speaking world for over 400 years since its first publication in 1611. The translation practice associated with it also constitutes a valuable legacy from which China can derive inspirations, especially for her foreign-oriented literature translation, in conjunction with the "One Belt, One Road" initiative. In terms of successfully replicating the practice of the KJB project, the state's leading role in organization is indispensable for large-scale translation projects and strong financial support is very important, too. Besides, in the long run, the reform of curriculum policy must commence right away to enable the cultivation of future talent with the cause of foreign-oriented literary translation in mind. Last but not least, in the final translating stage, talented individuals from abroad can make use of their correction, modification, and polishing skills. In short, all positive factors should be incorporated to ensure a splendid future for Chinese literary diffusion throughout the world.

\section{References}

British Broadcasting Corporation (BBC) Web. (2017). How it changed the way we speak? Retrieved November 24, 2017, http://www.bbc.com/news/magazine-12205084

Chen, B. (2016). On Chinese cultural communication and propagation. In Bureau for External Cultural Relations, Ministry of Culture, \& Translators Association of China (Eds.), Ferryman: Sino-foreign cultural translation and propagation (pp. 98-104). Beijing: Central Edition and Translation Publishing House.

Chen, X. (2017). Is 500 yuan per thousand words for translation high or not? Retrieved December 11, 2017, from http://news.xinhuanet.com/book/2017-12/11/c_129762124.htm

Croft, P. (2011). The emergence of the King James version of the Bible (1611). Theology, 114(4), 243-250.

Hong, Q. (2013). A brief introduction to English Bible versions (670-1611). Dongwu Acadamics, 5, 124-134.

Hu, A. (2010). Translator model, translating strategy, and the "Going Out" Project (Mode/Pattern) promote Chinese literature abroad: With American sinologist Howard Goldblatt as an exemplar. Chinese Translators Journal, 31(6), 10-16, 92.

Kang, K. (2011). 400th Anniversary of the completion of the King James Bible: When God spoke English. China Newsweek, 18, 58-59.

King James Bible (KJB) Translators. (2017a). Introduction. Retrieved November 24, 2017, from http://kingjamesbibletranslators. org/bios

KJB Translators. (2017b). Miles Smith. Retrieved November 24, 2017, from http://kingjamesbibletranslators.org/ bios/Miles_Smith/

Lin, L. (2016). Seemingly useless usefulness: How to give full play to College Chinese. Journal of Shandong Radio and TV University, 3, 39-42.

Liu, C., \& Wu, X. (2006). The translation of the Bible into English and the Authorized Version. Nationalities Research in Qinghai (Social Sciences), 3, 167-170. 
Liu, X. (2009). Review of translating Mao's works. Chinese Translators Journal, 5, 5-8.

Shi, K., \& Lv, J. (2013). Literature publishing towards the world: Who are to translate?-On subjectivity of translators of Chinese literature books. China Publishing Journal, 8, 57-60.

Shoulson, J. (2016). The King James Bible across borders and centuries. Milton Quarterly, 2, 88-91.

State Administration of Press Publication, Radio, Film and Television of The People's Republic of China (SAPPRFT). (2017). Notification on applying for the China classics international project, key translation project supported by the Silk Road Book Project and the Project of Modern Chinese Works. Retrieved January 19, 2017, from http:/ /www.sap-prft.gov.cn/sapprft/ contents/6588/313328.shtml

The 21st Century Web. (2017). King James Bible: A cornerstone of modern English. Retrieved July 14, 20 17, http://paper.i21st. $\mathrm{cn} /$ story/68261.html

Wang, G. (2014). A study of post-1949 translation of Chinese literature and its propagation effect. Southeast Communication, 6, 146-149.

Yang, P. (2008). The King James Bible: A masterpiece of scriptural translation. Shandong Foreign Language Teaching Journal, 2 , $81-85$.

Zhao, D. (2013). Analyzing the causes of overall weakening of Chinese literature translation. Journal of Zhongzhou University, 4, 77-79. 